\title{
A TRANSFORMAÇÃO DA PRÁTICA JUDICIÁRIA COM A IMPLANTAÇÃO DO PROCESSO ELETRÔNICO
}

\section{THE TRANSFORMATION OF JUDICIAL PRACTICE WITH THE IMPLEMENTATION OF THE ELECTRONIC PROCESS}

\author{
Graziele Lopes Ribeiro' \\ Kauã Pereira Wanderley ${ }^{2}$
}

\section{RESUMO}

O congestionamento de processos sobrecarrega o Poder Judiciário brasileiro e interfere diretamente na qualidade e eficiência da prestação jurisdicional à sociedade. Nesse cenário, desenvolveu-se uma ferramenta tecnológica cujo objetivo é a celeridade processual. A digitalizaram dos processos e migração para o sistema e-proc minimizaram o congestionamento judicial. O Tocantins foi o primeiro estado brasileiro a ter $100 \%$ dos processos digitalizados e desde então a taxa de congestionamento tem diminuído e a de produtividade aumentado. O presente trabalho pretende verificar se a ferramenta do e-proc propicia a celeridade processual e eficiência na prática de prestação de serviços aos cidadãos e na prática judiciária para os operadores do Direito no Tribunal de Justiça do Estado do Tocantins, através da análise comparativa do sistema e-proc nas varas criminais do Tribunal de Justiça do Estado do Tocantins (TJTO) no período de 2011 a 2016. O caminho metodológico consistiu numa pesquisa documental com análise de relatórios de gestão do Tribunal de Justiça do Tocantins. Concluiu-se que, houve uma diminuição na taxa de congestionamento de processos após a implantação de e-proc e diversas outras vantagens que acarretam na melhoria da prestação jurisdicional.

Palavras-chave: Processo Judicial. Celeridade Processual. Resolução de Conflitos. E-proc.

\section{ABSTRACT}

The congestion of cases overloads the Brazilian Judiciary and directly interferes with the quality and efficiency of the judicial provision to society. In this scenario, a technological tool has been developed whose objective is procedural speed. The digitization of processes and migration to the e-proc system minimized judicial congestion. Tocantins

\footnotetext{
1 Doutoranda em Direito pela Faculdade Autônoma de São Paulo, Mestre em Direito Internacional Econômico pela Universidade Católica de Brasília, Graduada em Direito pela Universidade de Marília com estudos de pós-graduação em direito, Professora do Curso de Direito do Centro Universitário Luterano de Palmas. grazielelopesribeiro@hotmail.com. ORCID ID https://orcid.org/0000-0003-1028-3262

${ }^{2}$ Graduando em Direito pelo Centro Universitário Luterano de Palmas. E-mail: kauapw@gmail.com. ORCID ID https://orcid.org/0000-0002-8526-6312
} 
was the first Brazilian state to have $100 \%$ of the processes digitalized and since then the congestion rate has been decreasing and the productivity rate has increased. This paper aims to verify if the e-proc tool provides procedural speed and efficiency in the practice of providing services to citizens and in the judicial practice for legal operators in the Tocantins State Court of Justice, through the comparative analysis of the system. e-proc in the criminal courts of the Tocantins State Court of Justice (TJTO) from 2011 to 2016. The methodological approach consisted of a documentary research with analysis of management reports of the Tocantins Court of Justice. It was concluded that there was a decrease in the congestion rate after e-proc was implemented and a number of other advantages that lead to the improvement of the court provision.

Keywords: Judicial Process. Procedural Speed. Conflict resolution. E-proc.

\section{INTRODUÇÃO}

O desenvolvimento tecnológico impeliu a mudança do processo físico para o processo eletrônico. A promulgação da Lei no 11.419 introduziu significativas mudanças nos trâmites processuais tornando a prestação jurisdicional mais célere.

A informatização do sistema judiciário no Brasil, com o intuito de agilizar os procedimentos judiciais, iniciou-se em 1991 por meio da promulgação da Lei no 8.245/91. Desde então, o modus operandi vem sendo modificado e alterado conforme as necessidades dos operadores de Direito para garantir a eficiência do serviço prestados aos cidadãos tanto nas esferas penal, civil ou trabalhista.

A utilização dessas novas tecnologias na automação de processos trouxe vantagens como a economia no uso de papel, o baixo custo operacional e a celeridade dos meios administrativos no procedimento judicial, assim como algumas desvantagens como a sobrecarga de servidores, alto custo na aquisição de equipamentos eletrônicos e capacitação de profissionais.

O presente estudo apresenta-se relevante tanto do ponto de vista acadêmico, social e funcional para os operadores que utilizam a ferramenta sob análise - e-proc bem como para a sociedade que busca o acesso e a prestação judicial de competência do Estado.

Para tanto, este trabalho pretende traçar a evolução histórica dos conflitos sociais, relatar o contexto histórico do processo físico e processo eletrônico no Brasil e, por fim, apresentar como se deu a implementação do e-proc. no Tribunal de Justiça do 
Tocantins, listar suas vantagens e desvantagens e comparar a quantidade de processos finalizados antes e depois o advento do sistema, através da análise da taxa de congestionamento do referido tribunal.

\section{A RESOLUÇÃO DE CONFLITOS SOCIAIS}

Os conflitos sociais fazem parte da existência e da sociabilidade humana desde os primórdios até os tempos atuais, porém em distintas proporções. É evidente que o surgimento de conflitos sociais decorre de desejos particulares, de forma que, para alcançar sua pretensão o indivíduo é capaz de agir de maneira injusta para com os demais, gerando assim, desentendimentos (SOUSA, 2013).

Daí o motivo pelo qual a evolução histórica é marcada por conflitos, muitas vezes associada à violência como no caso de guerras entre comunidades ou mesmo de um indivíduo para com outro. Observa-se que a violência teve um papel contrário à evolução humana, pois não servia para resguardar a vida, mas atuava como parâmetro de dominação, instrumento para a resolução de conflitos. (VASCONCELOS, 2008).

Registros históricos apontam que a primeira forma de resolução de conflitos sociais se deu por meio da autotutela, conhecida como "justiça com as próprias mãos", em que prevalecia a decisão do indivíduo mais forte, mais inteligente ou mais esperto, sendo esta a forma mais primitiva de resolução de conflitos que se tem conhecimento até 0 alcance do atual processo judicial com suas garantias constitucionais (GONÇALVES, 2016).

$\mathrm{Na}$ busca de uma existência confortável, a sociedade notou a necessidade da criação de um ente maior que fosse responsável por mediar às relações sociais e positivar regras, a fim de alcançar a manutenção da ordem, na qual a busca se daria pelo interesse coletivo, e não somente pelo interesse particular, de alguns (VASCONCELOS, 2008).

No decorrer da evolução histórico-política e social, a pacificação da resolução de conflitos sociais surgiu quando a sociedade fez jus à relação entre justiça e dignidade da pessoa humana, que nasceu com a implementação do Estado Democrático de Direito, decorrente da luta contra o Absolutismo no qual se firmou os direitos naturais da pessoa humana (BOBBIO, 1992). 
Cintra, Grinover e Dinamarco (1998) afirmam que tal mudança se deu em virtude de que pouco a pouco a sociedade percebeu os males deste sistema pernicioso e começou a referir uma solução parcial dos conflitos, de modo que, com a presença de um terceiro a decisão se pautaria na convicção coletiva e nos costumes.

A introdução de um terceiro na resolução de conflitos desencadeou um novo sistema de resolução de contendas que da mediação fez surgir a arbitragem e posteriormente a jurisdição estatal.

No Brasil, a Constituição Federal de 1988 trouxe para a superação de conflitos instrumentos de tutela jurisdicional para o acesso à justiça a fim de garantir e não apenas proclamar o direito de todos, sendo eles derivados da autocomposição, heterocomposição e método jurisdicional (CINTRA, GRINOVER, DINAMARCO, 2010).

A jurisdição é a capacidade do Estado em decidir imperativamente e impor decisões com o devido processo legal, a fim de que seja encontrada uma solução justa para a lide, sendo a função própria do Estado e que possui três formas distintas para seu exercício: o poder exercido pelo próprio Estado, a função exercida pelos agentes no cumprimento das decisões tomadas e a atividade que se dá por meio da ação do juiz no processo (DINAMARCO, GRINOVER, CINTRA, 2006).

O método jurisdicional configura o poder estatal de modo que o direito de ação é assegurado a todos, e o cidadão exerce esse direito ao provocar o exercício da atividade jurisdicional que é dotada de imparcialidade, definitividade, inércia, unidade, lide e substitutividade, tendo suas ações direcionadas ao interesse público (ALMEIDA FILHO, 2015).

A função jurisdicional que se desenvolve por meio do processo, e está intimamente ligada os princípios do devido processo legal, da imparcialidade, do contraditório, da ampla defesa, da fundamentação, da publicidade, da celeridade e do duplo grau de jurisdição (MACHADO; MIRANDA, 2010).

\section{O PROCESSO}

O Direito tem passado por diversas evoluções no decorrer dos anos evoluindo do processo tradicional, o físico com uso do papel, para instrumentalizar as novas 
possibilidades oferecidas pelos meios tecnológicos, com vistas a amenizar a morosidade da justiça, reduzir os custos processuais, bem como a eliminação de documentos de papel que poluem e prejudicam o meio ambiente (BROTTO, 2009).

O processo eletrônico designado como e-process, foi instituído no país com a finalidade de acelerar o trâmite processual o tornando mais ágil e eficiente. $O$ inciso LXXVIII da Constituição Federal de 1988, com a redação determinada pela Emenda Constitucional n. 45/04, estabelece a duração razoável do processo e a celeridade na prestação jurisdicional garantido ao cidadão (ABRÃO, 2011).

Ainda há Leis Federais № 11.187/05, 11.232/05, 11.276/06, 11.277/6, 11.280/06 e 11.341/06 que fazem parte da terceira fase da reforma do sistema processual civil. 0 Poder Judiciário ao utilizar essa nova tecnologia na automação de processos faz uso de várias vantagens como a economia no uso de papel, o baixo custo operacional e a celeridade dos meios administrativos no procedimento judicial (GONÇALVES, 2015).

O objetivo da Lei oㅜ 11.419, promulgada em 19 de dezembro de 2006, é regulamentar a comunicação de peças processuais por meios eletrônicos na esfera civil, trabalhista e penal, sendo que para uma maior eficiência e celeridade os órgãos públicos devem adotar mecanismos que facilitem o repasse de informações sobre os processos judiciais nos sites adotados para a utilização e disseminação do conteúdo dos processos aos cidadãos (MALLMANN, 2016).

A operacionalização dos processos judiciais, além de ser uma novidade na reforma do Judiciário contribui para fazer jus aos princípios da Constituição Federal Brasileira que impõe a celeridade processual, o acesso à justiça e a dignidade humana. A reforma do Judiciário no que diz respeito à adoção do sistema eletrônico permite que qualquer cidadão de qualquer lugar possa acessar informações judiciais e até mesmo conseguir uma impressão de processo judicial pelo site do Poder Judiciário (ABRÃO, 2011).

A serviço da estatística e da produtividade o processo automatizado proporciona diversos pontos positivos de interesse da Justiça como o cumprimento do prazo legal estabelecido, o que atualmente com a quantidade de processos e recursos, faz com que a celeridade na tomada de decisões pelos magistrados diminua. A respeito dos serventuários da Justiça a adoção ao sistema virtual não tem o propósito de gerar a 
demissão de pessoal. Pois os que tiverem seus serviços substituídos pelo e-process, podem ser remanejados para outras áreas (GONÇALVES, 2015).

$O$ intuito do legislador com o processo virtual é dar celeridade e efetividade na regulamentação processual e sentenças mais rápidas para o ordenamento jurídico. Há anos, o Judiciário busca uma forma de prestação jurisdicional eficaz e de qualidade que visam desafogar a quantidade de processos que afogam o sistema (ABRÃO, 2011).

O desafogamento e a celeridade de processos judiciais diminui a sobrecarga dos tribunais judiciários o que torna mais rápido o desenvolvimento das ações. O Poder Judiciário Brasileiro encontra-se em uma crise do sistema jurisdicional, devido ao congestionamento de processos pendentes. "O pior de tal crise é a incapacidade de tomar decisões e de solucionar os conflitos, impeditivo este da efetividade dos direitos como dignidade humana e acesso à justiça característicos do estado constitucional" (SLONGO, 2009).

Isso porque o retardo judicial agrava com a excessiva quantidade de recursos utilizados e previstos, mesmo que procrastinatórios, nos Códigos processuais. $\mathrm{O}$ princípio da eficiência anexado ao da finalidade, legalidade, motivação, moralidade, ampla defesa, contraditório, segurança jurídica, razoabilidade e do interesse público abrange todo o texto constitucional (MALLMANN, 2016).

Já o acesso à justiça é um princípio garantido para a jurisdição segura e efetiva do direito de ação. Não cabe somente ao cidadão receber acesso, mas sim, obter uma jurisdição eficiente e de qualidade. Pois a eficiência é um dever da Administração (ALMEIDA FILHO, 2015).

Elenca-se ainda 0 artigo $5^{\circ}$, incisos LXXVIII e XXXV, da Constituição Federal estão presentes respectivamente, o princípio da celeridade processual e o princípio constitucional de garantia de acesso à justiça que norteiam a implantação do processo eletrônico (BRASIL, 1988).

O princípio da celeridade processual também conhecido como da brevidade é o meio pelo qual a jurisdição opera. Segundo Portanova (2005, p. 171), "o processo deve ter andamento o mais célere possível". Barbosa (2007) destaca que a observância da celeridade processual ocorre quando se manifesta a redução do tempo de tramitação 
do processo, abrevia o comando contido na sentença e restitui paz social entre as partes.

O acesso à justiça pode, portanto, ser encarado como o requisito fundamental de um sistema jurídico moderno e igualitário que pretenda garantir, e não apenas proclamar os direitos de todos (CAPPELLETTI, 1988).

Outros princípios também são assegurados através do processo eletrônico é o da igualdade, ampla defesa, contraditório e da publicidade. "A maioria dos princípios processuais inerentes à jurisdição se aplica ao processo eletrônico" (GRECO FILHO, 2008, p.74).

Nesse sentido, o surgimento do processo eletrônico foi mudança favorável à Justiça Brasileira. Com ele os processos adquirem maior celeridade processual e a inovação tecnológica diminuirá substancialmente a quantidade de processos que congestionam o sistema judiciário (ALMEIDA FILHO, 2015).

Atualmente, esta inovação está consolidada e é utilizada senão por todos, mas pela maioria dos Tribunais do país, pois é uma realidade nacional. Isso significa na transformação de tribunais e varas em um meio digital, na criação de assinaturas eletrônicas, na economia de papel e o principal, o acompanhamento do trâmite de processos pelo sistema de sites (GONÇALVES, 2015).

Os tempos mudaram, e também com eles as perspectivas e os escopos do denominado direito adjetivo, que hoje, precisa observar a necessidade de alinhamento do direito processual com os modernos postulados do acesso à justiça (CHAVES, 2006).

Uma das grandes vantagens desse processo é a desburocratização, pois será possível a prática dos atos processuais sem a intermediação de cartório ou de secretaria. As petições em formato digital poderão ser juntadas aos autos do processo eletrônico diretamente pelos advogados, com imediato fornecimento de recibo eletrônico de protocolo (DESTEFENNI, 2009, p. 174).

Além de combater a morosidade de processos judiciais, o processo eletrônico traz outras vantagens como a economia de dinheiro público, de tempo e até mesmo de espaço físico. Contudo, continuará com a mesma segurança e sigilos dos dados e com informação disponível em todos os dias da semana e a qualquer horário (CONJUR, 2018). 
Contudo, apesar das vantagens há também desvantagens decorrentes de correções e adequações de sistema e ferramentas. Dentre elas: a segurança do sistema pode ser burlada por meio de invasores que buscam alterar/modificar dados; a dificuldade de harmonização de critérios no âmbito nacional; dificuldade de assimilação acerca do uso da ferramenta pela população; inviabilização da leitura do servidor, alto custo para aquisição de equipamentos eletrônicos, congestionamento do sistema, sobrecarga para os operadores e alegações de nulidades no procedimento penal (MEDINA, 2011).

Observa-se, portanto, que a implementação do e-proc. traz consigo vantagens e desvantagens em sua utilização, todavia, é necessário uma atenção para que as desvantagens não obstruam o caminho para a eficácia da ferramenta, que surgiu da necessidade de acelerar os procedimentos administrativos na esfera judicial e assim promover o acesso à justiça conforme os princípios constitucionais.

No estado do Tocantins, a regulamentação do sistema eletrônico teve início com a Resolução nº 001, e a implementação com o Termo de Cooperação Técnica firmado entre o TJTO e o Tribunal Regional Federal da 4⿳亠丷厂 Região - TRF 4⿳亠丷. .

A fim de normatizar o uso do processo eletrônico na tramitação de processos judiciais, transmissão de peças processuais no âmbito estadual e comunicação de atos foi regulamentada a Instrução Normativa ํo 05 de 24 de outubro de 2011, cuja definição traz que:

Art. 2 Parágrafo único... I - e-Proc/TJTO, o sistema de processo eletrônico utilizado pelo Poder Judiciário do Estado do Tocantins; II - meio eletrônico, qualquer forma de armazenamento ou tráfego de documentos e arquivos digitais, devendo ser usado exclusivamente arquivos no formato PDF (portable document format) para textos, JGP (Joint Photographic Experts Group) para fotos e MP3 ou WMA para arquivos de áudio; III - autos eletrônicos, o conjunto de documentos e atos processuais produzidos e registrados no e-Proc/TJTO; IV - transmissão eletrônica, toda forma de comunicação à distância de arquivos digitais com a utilização, preferencialmente, da rede mundial de computadores internet; V - assinatura eletrônica, as seguintes formas de identificação inequívoca do signatário: a) assinatura digital baseada em certificado digital emitido por autoridade certificadora credenciada, na forma de lei específica; b) cadastro de usuário no Poder Judiciário, conforme disciplinado nesta Resolução e na Portaria no 116/2011/TJTO. VI - endereço eletrônico, página na internet de acesso ao sistema e-Proc/TJTO (TOCANTINS, 2011a). 
Na sequência, a Instrução Normativa no 05 definiu que os usuários do eProc./TJTO, conforme o artigo 7ํ, sendo eles: desembargadores, juízes, servidores e auxiliares autorizados do Poder Judiciário do Estado do Tocantins; e externos: partes, advogados, defensores, procuradores, membros do Ministério Público, policias, peritos e outros interessados ou intervenientes na relação jurídico-processual (TJTO, 2011).

Sobre a responsabilidade dos usuários, a Instrução Normativa nº 05 traz ainda que é exclusivo:

I - o sigilo da chave privada de sua identidade digital;

II - a exatidão das informações prestadas;

III - o acesso ao seu provedor da internet e à configuração do computador utilizado nas transmissões eletrônicas de acordo com os requisitos estabelecidos no endereço eletrônico do TJTO;

IV - a confecção de petições e documentos no e-Proc/TJTO em conformidade com o formato e o tamanho definido no endereço eletrônico do TJTO;

V - o acompanhamento da divulgação dos períodos em que o serviço não estiver disponível em decorrência de manutenção no endereço eletrônico do TJTO;

$\mathrm{VI}$ - o acompanhamento do regular envio e recebimento das petições e documentos transmitidos eletronicamente;

VII - o sigilo dos registros audiovisuais em meio eletrônico, devendo arcar com as consequências da divulgação não autorizada, nos termos do art. 20 da Lei nำ 10.406/2002 (Código Civil) (TOCANTINS, 2011a).

Em se tratando de sigilo das informações, o artigo 19 dispõe sobre os níveis que poderão ser atribuídos ao feito, documento ou evento pelo juízo processante:

I - Nível zero - Autos Públicos (visualização por todos os usuários internos, partes do processo e por terceiros, sendo que estes devem estar munidos da chave do processo);

II - Nível um - Segredo de Justiça (visualização somente pelos usuários internos e partes do processo);

III - Nível dois - Sigilo (visualização somente pelos usuários internos e órgãos públicos previamente credenciados);

IV - Nível três - Sigilo (visualização somente pelos usuários internos do juízo em que tramita o processo);

V - Nível quatro - Sigilo (visualização somente pelos usuários com perfil de Magistrado, Escrivão, Diretor de Secretaria e Chefe de Gabinete);

$\mathrm{VI}$ - Nível cinco - Restrito ao Juiz (visualização somente pelo Magistrado ou a quem ele atribuir).

Parágrafo único. A permissão de visualização dos processos pelos demais operadores do Direito obedecerá ao que for previsto em lei (TOCANTINS, 2011a). 
Em 15 de junho de 2011, a presidente do Tribunal de Justiça, Desora Jaqueline Adorno, baixou a Portaria no 244 determinando a implantação do e-proc/TJTO nas Varas Cíveis de Palmas, Câmaras Cíveis Tribunal Pleno do Tribunal de Justiça, convalidando todas as petições protocoladas desde então. De maneira, que a implantação se deu pela capital do estado seguindo para as Comarcas do interior. Em setembro de 2012 foi finalizada a instalação do sistema de virtualização dos processos nas 42 comarcas; e em 2015 o Tocantins se tornou o primeiro estado a ter o Judiciário $100 \%$ eletrônico, pois todos os processos em andamento estavam digitalizados.

As audiências são registradas em meio eletrônico e todos os arquivos correspondentes são anexados ao e-proc. Em caso de depoimentos, eles devem ser registrados em meio digital, conforme os que o sistema permite, e posteriormente arquivado no e-proc (TOCANTINS, 2011).

Em hipóteses de indisponibilidade do sistema decorrente de falha de equipamentos e transmissão e acesso ao banco de dados ou quaisquer outros motivos, a Instrução Normativa no 002 dispõe no artigo 6o que a petição inicial pode ser protocolizada por meio físico para distribuição manual e posterior digitalização e inserção no sistema, de forma a em nenhuma hipótese prejudicar o direito à liberdade de locomoção e o perecimento do direito e ofensa (TOCANTINS, 2011).

Em 2018, o sistema de processo eletrônico no TJTO completou sete anos de utilização e o site institucional divulgou que mais de 1,2 milhão de processos estão cadastrados em sua base de dados, seja de processos em andamento, que já tramitaram ou que já foram concluídos (TJTO, 2017).

\section{VANTAGENS E DESVANTAGENS DO SISTEMA}

A principal função do processo eletrônico é tornar a Justiça brasileira mais célere, oferecendo assim, diversas vantagens devidas sua utilização via sistemas eletrônicos no "acompanhamento de etapas e fases procedimentais, mas, sobretudo, priorizar velocidade compatível com a natureza do litígio" (ABRÃO, 2011, p. 09). 
São indiscutíveis as vantagens trazidas pelas novas tecnologias que vão desde a diminuição do uso do papel quanto à movimentação do advogado e dos envolvidos às unidades judiciais como fóruns e tribunais para o cumprimento de prazos (MARQUES, PEREIRA, 2016).

Com os recursos eletrônicos é possível acionar a Justiça de qualquer lugar para realizar consultas e petições, elaboração de sentenças e despachos rompendo assim, as restrições de tempo e de espaço, de forma que, os documentos e petições são protocolados até às $24 \mathrm{~h}$ do seu último dia, ou seja, os atores processuais ganharam mais prazo, do que o do expediente da instalação física do órgão judicial, para fazê-lo. (SOARES, 2012).

Conforme Abrão (2011) a informatização do processo judicial provocou mais agilidade na tramitação dos atos judiciais, a redução de custos com procedimentos e incidentes, garantia de acesso aos procedimentos, mais transparência, menor volume de autos físicos que corriam riscos de extravios e uma melhor sintonia entre a segunda e primeira instância.

Sendo os autos virtuais, diminui-se o risco de danos, extravio de documentos e processos, que ensejariam procedimentos de restauração de autos. Outrossim, proporciona agilidade na remessa do processo para a $2^{\circ}$ instância e economia das custas do porte de remessa e retorno, que são cobradas apenas em relação aos processos físicos. Quanto ao cumprimento das cartas precatórias, poderá ser realizado em menor tempo, economizando o prazo de envio e retorno. Podemos citar como outro avanço processual a eliminação de tarefas demoradas como juntadas, autuações de autos, e outras burocracias. Mais uma grande vantagem do processo eletrônico é o espaço físico que deixará de ocupar. As pilhas de processo deixarão de existir. O meio ambiente agradece a economia de papel e outros acessórios, como a tinta de impressora (PAPA, 2013, p. 1).

Assim como expõe Neto (2015, p. 15), no caso da " remessa do processo para a $2^{\circ}$ instância é realizada com muito mais agilidade e economia de custas, que são cobradas nos processos físicos". 
A tecnologia contribuiu para uma significativa redução nos gastos públicos judiciais tanto para o Estado, quanto para os usuários do sistema, o cidadão. Do ponto de vista de recursos materiais, é inegável a economia do uso de papel, tintas, carimbos, grampeadores, cartuchos de impressoras, que certamente diminuem o impacto ambiental (ABRÃO, 2011).

Neste sentido, Teixeira (2014) explica que:

[...] Antes do advento do processo eletrônico, por ano, eram consumidas aproximadamente 46.000 toneladas de papel pelos processos judiciais impressos do Brasil, o que equivale a 690.000 árvores. Cada processo físico custava em média $\mathrm{R} \$ 20,00$ entre papel, grampos etc. Considerando que à época eram cerca de 70 milhões de processos em andamento, o custo anual ficava em $R \$ 1.400 .000 .000$. Esse número seria ainda maior ao se considerar que o ano de 2012 foi encerrado com 92 milhões de processos em andamento, conforme levantamento do Conselho Nacional de Justiça (TEIXEIRA, 2014, p. 446).

Sobre o impacto ambiental, a diminuição da utilização de papel é de grande valia, pois conforme Prestes (2007, p. 1), cerca de "vinte e duas árvores são cortadas para se fazer uma tonelada de papel, sendo necessários 100.000 (cem mil) litros de água e 5.000 (cinco mil) Kw/h de energia elétrica".

Além da economia de papel, os sistemas eletrônicos reduzem o desgaste do processo, a morosidade da prestação jurisdicional, trazendo mais segurança e celeridade no processamento da lide. Conforme o Conselho Nacional de Justiça a utilização do processo eletrônico constitui num maior controle da transparência administrativa e processual dos tribunais (MARQUES, PEREIRA, 2016).

$\mathrm{Na}$ gestão de pessoas, o processo eletrônico alterou os procedimentos diários dos operadores do Direito e consequentemente suas condições de trabalho e de saúde, assim como declara Teixeira (2014):

[...] O processo eletrônico trará muitas vantagens à parte, aos patronos, ao judiciário e à sociedade em geral. Irá possibilitar, entre outras coisas, a diminuição do trabalho braçal dos serventuários, bem como dos custos com afastamento por acidente ou doenças (por exemplo: respiratórias, de coluna etc.) (TEIXEIRA, 2014, p. 444). 
Tal fato se explica devido à ausência de movimentação de processos físicos volumosos e pesados dos autos do processo, que eram manuseados por juízes e servidores, acarretando na diminuição do desgaste físico dos serventuários da Justiça (ADORNO JUNIOR; MUNIZ, 2016).

Outra vantagem diz respeito à publicidade, que conforme explana Paula (2009, p. 11), "as novas tecnologias de comunicação e informação nos conduzem no fio da navalha entre os anseios democráticos por transparência e os imperativos de garantia da intangibilidade da privacidade". O processo eletrônico possibilita total acesso aos dados processuais, desde que não estejam sob segredo de justiça. Conquanto, a íntegra dos autos só pode ser acessada pelo Ministério Público, as partes e seus advogados.

Quanto à automatização da tramitação processual e dos atos praticados, Neto (2015) discorre sobre o que a doutrina majoritária chama de "tempo morto" ou "tempo inútil" do processo, que é uma realidade no sistema jurisdicional brasileiro, que devido à burocracia estatal judiciária, o processo fica parado por um lapso temporal excessivo aguardando providências, e assim, viola o princípio constitucional da razoável duração do processo.

Segundo Soares (2012), o meio eletrônico faz com que tempo do processo relacionado a atos de remessa, carimbagens, numeração e conclusão, dentre outros, sejam feitos automaticamente pelo sistema do e-proc, não havendo necessidade de um servidor para realizar os devidos trâmites.

Dentre as desvantagens, Marques e Pereira (2016) explicitam a segurança e autenticidade dos documentos na forma digital. Insegurança esta que surgiu no início com a implementação do processo eletrônico em todo país, devido aos mecanismos de proteção de documentos, que tem atenção total na utilização do e-proc pelos órgãos da Justiça e que passam por constantes adequações e atualizações, em busca de manter a autenticidade dos documentos anexados em processo eletrônicos.

Quanto à autenticidade de documentos eletrônicos, Greco coloca que "o documento eletrônico oficialmente autenticado tem a eficácia de uma escritura privada, gerando presunção de certeza de providência das declarações de quem o subscreveu" (GRECO et al., 2001, p.89). 
Assim, advogados, auxiliares da Justiça e juízes fazem uso de um certificado digital que é uma assinatura digital que contém dados do titular e do seu emissor, vinculando a pessoa a uma chave pública.

De modo que:

\begin{abstract}
Através de um sistema de codificação e, posteriormente, decodificação, pelas nominadas chaves simétricas e assimétricas, se pode verificar a autenticidade da assinatura. Caso não haja a decodificação de forma correta, o sistema identifica e o documento é rejeitado. Trata-se de segurança necessária para as transações comerciais e em especial para a utilização de transmissão de atos processuais por meio eletrônico (ALMEIDA FILHO, 2010, p. 142).
\end{abstract}

No contexto operacional do sistema de processo eletrônico é exigido um alto custo para manutenção de equipamentos eletrônicos para digitalização e manutenção do documento digital, computadores eficientes, softwares atualizados e técnicos (MARQUES; PEREIRA, 2016).

A indisponibilidade do sistema também é uma desvantagem para a prática judiciária, caso ocorra, seja por falta de energia, ausência de internet, dentre outros fatores. Assim, é necessário práticas de segurança da informação para possíveis perdas de dados, os backups são boas alternativas com custo viável (NETO, 2015).

A lentidão no acesso ao sistema devido a sobrecarga de uma grande quantidade de usuários nos computadores responsáveis pelo processamento do sistema, que pode ser corrigido com uma infraestrutura tecnológica de informação e comunicação adequada a fim de garantir a performance e estabilidade do sistema e do software utilizado pelo e-proc (NETO, 2015).

$\mathrm{Na}$ gestão de pessoas, convém ressaltar uma desvantagem da utilização de computadores por tempo em demasia pode causar problemas relacionados à visão, lesões por esforço repetitivo e problemas de má postura, além da dificuldade de pessoas com deficiência visual para a acessibilidade do sistema (FOLLE; SHELEDER, 2014). 
Destaca-se ainda, a falta de magistrados para o julgamento de processos, pois de nada adianta um sistema célere, se não houver operadores do Direito e juízes a contento para dar seguimento e desfecho aos processos no mesmo ritmo do sistema de processo eletrônico (FOLLE; SHELEDER, 2014).

Em 2011, a produtividade do Tribunal de Justiça do Estado do Tocantins (TJTO) teve um total de 574 processos, de modo que, 238 eram processos físicos (41\%) e 336 virtuais (59\%). Já em 2012 foram 741 processos virtuais distribuídos, não havendo processos físicos, sendo $100 \%$ da demanda realizada de forma eletrônica, segundo a Secretaria do Tribunal Pleno.

Sobre os processos julgados, a estatística aponta que em 2011, de 374 processos. Destes 313 foram de processos físicos, que corresponde a $84 \%$, e de 61 virtuais (16\%), sendo que, já em 2012, de 702 processos julgados, 123 foram físicos $(18 \%)$ e 579 processos virtuais, que corresponde a $82 \%$. Nota-se que houve um grande avanço na utilização de processo virtual, isto é, do uso do e-proc.

Em 2011, os processos criminais de $1^{\text {a }}$ e 2 a Câmara Criminal autuados foram 2.503 e baixados o quantitativo de 2.123 , conforme o TJTO. Não foram encontrados dados que distinguissem ao quantitativo de cada Câmara Criminal para uma melhor descrição e apresentação dos mesmos, conforme será feito nos demais anos.

Em relação à implantação do e-proc no Judiciário, a então presidente do TJTO, a desembargadora Jacqueline Adorno de La Cruz Barbosa destacou que as rotinas de adaptação da virtualização dos processos judiciais no estado foram uma preocupação da gestão de 2011 (TJTO, 2012).

Tanto que foram promovidos cursos de capacitação profissional para a utilização do e-proc em 2011, os servidores do TJTO, bem como Juízes das varas receberam treinamento da Escola Superior de Magistratura (ESMAT) sobre a utilização do e-proc para aprenderem a operar o sistema com carga horária de oito horas (TJTO, 2011).

Após quase ano e meio após a implantação do e-proc no TJTO, que ocorreu em 06/06/2011, a ferramenta possui quase a totalidade do acervo físico de processos que foram informatizados. Convém destacar que, em âmbito nacional o TJTO foi o primeiro estado a ter o Judiciário $100 \%$ eletrônico, com a eliminação do papel ao digitalizar todos os processos em andamento (TJTO, 2017; TJTO, 2013). 
No relatório seguinte que traz informações do ano de 2013, o TJTO se preocupou em acompanhar o avanço tecnológico para a melhoria da prestação jurisdicional, de forma que, o acervo digital dos processos e a utilização do processo eletrônico tornavam os trâmites mais transparentes e céleres. Conforme o TJTO, no início de 2013 havia 380 processos físicos em trâmite, sendo que, no final do exercício do referido ano restavam somente 50 processos para digitalização (TJTO, 2014).

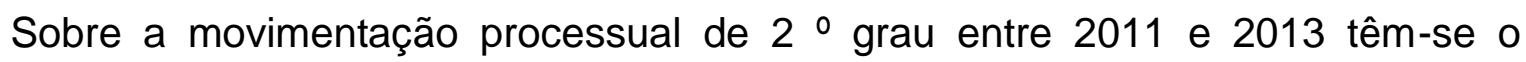
seguinte:

Quadro 1 - Movimentação processual de $2^{\circ}$ grau de 2011 a 2013

\begin{tabular}{|c|c|c|c|c|c|}
\hline \multirow{2}{*}{ Secretaria } & \multicolumn{2}{|c|}{ Processos baixados } & \multicolumn{2}{c|}{ Processos julgados } & \multirow{2}{*}{} \\
\cline { 2 - 5 } & $2011 / 2012$ & 2013 & $2011 / 2012$ & 2013 & Total \\
\hline $1^{\text {a }}$ Câmara Criminal & 2.021 & 1.232 & 2.796 & 1.092 & 7.141 \\
\hline $2^{\text {a }}$ Câmara Criminal & 1.765 & 1.189 & 2.041 & 1.261 & 6.256 \\
\hline Total & 3.786 & 2.421 & 4.837 & 2.353 & 13.397 \\
\hline
\end{tabular}

Fonte: Assessoria de Estatística TJTO.

Nota-se que houve 13.397 processos da Câmara Criminal de 2011 a 2013, sendo que, $53 \%$ (7.141) foram da $1^{\circ}$ Vara Criminal e $47 \%$ (6.256) da $2^{\text {a }}$ Vara Criminal. O quadro a seguir apresenta a movimentação processual de $2^{\circ}$ grau entre 2014 e 2016. 


\begin{tabular}{|c|c|c|c|c|c|c|c|}
\hline \multirow[b]{2}{*}{ Secretaria } & \multicolumn{3}{|c|}{ Processos baixados } & \multicolumn{2}{|c|}{ Processos julgados } & \multirow[b]{2}{*}{2016} & \multirow[b]{2}{*}{ Total } \\
\hline & 2014 & 2015 & 2016 & 2014 & 2015 & & \\
\hline $\begin{array}{l}\text { 1' Câmara } \\
\text { Criminal }\end{array}$ & 1.384 & 1.191 & 1.590 & 997 & 1.567 & 1.707 & 8.436 \\
\hline $\begin{array}{l}2^{\text {a }} \text { Câmara } \\
\text { Criminal }\end{array}$ & 1.240 & 1.033 & 1.615 & 1.115 & 1.566 & 1.677 & 8.246 \\
\hline Total & 2.624 & 2.224 & 3.205 & 2.112 & 3.133 & 3.384 & 16.682 \\
\hline
\end{tabular}

Fonte: Divisão de Distribuição e Câmaras do TJTO.

De 2014 a 2016 a 1a Câmara Criminal teve 51\% (8.436) processos e a $2^{\circ}$ Câmara com $49 \%$, ou seja, 8.246 processos. O Poder Judiciário de $2^{\circ}$ Grau contabilizou 8.340 processos em andamento até outubro de 2012. Desse quantitativo, $88 \%$ são processos que tramitam em meio eletrônico.

Conforme o TJTO (2016), desde 2014 100\% das Comarcas de $1^{\text {a }}$ e $2^{\text {a }}$ Entrância trabalham totalmente no processo eletrônico e mais de $50 \%$ das Varas das Comarcas de $3^{\text {a }}$ Entrância. De acordo com a estatística, em 2012 foram 1.692 processo digitalizados, em 2013 foram 40.799 e em 2014 foram 61.044, totalizando 101.843 mil processos físicos e digitalizados.

Convém destacar que, para o mérito da rápida digitalização dos processos físicos se deu em virtude de uma parceria do TJTO com o Exército Brasileiro, que por meio do $22^{\circ}$ Batalhão de Infantaria de Palmas, cedeu efetivo para auxiliar na digitação dos processos, sob a supervisão do Núcleo de Apoio às Comarcas (Nacon) (TJTO, 2016). 
Gráfico 1 - Percentual do congestionamento da meta 1 ( 2014/2015)

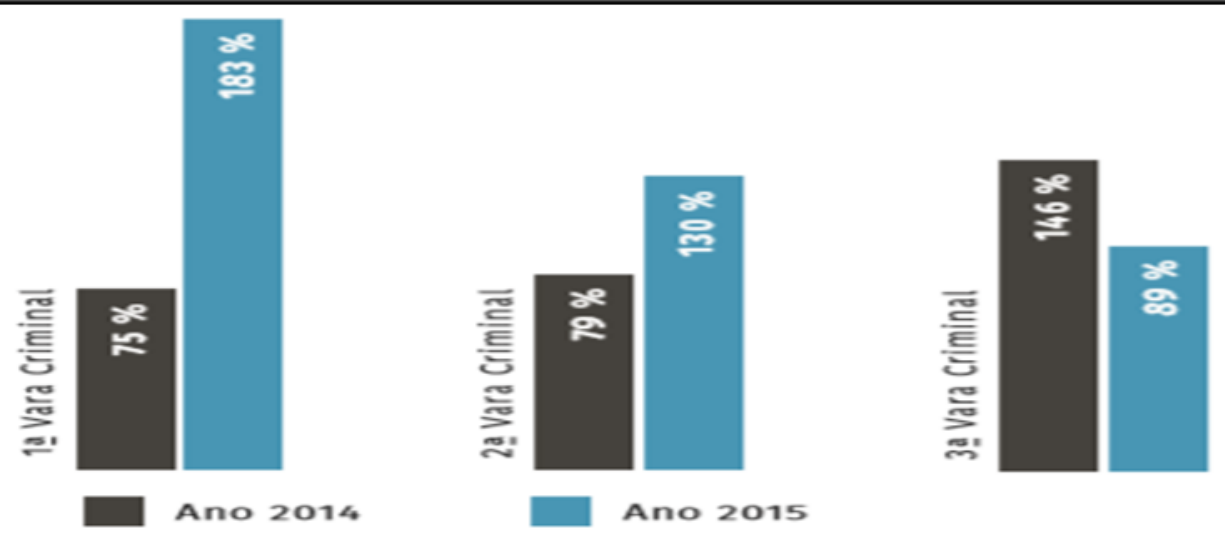

Fonte: TJTO (2015, p. 62).

As oito metas nacionais estabelecidas pelo Conselho Nacional de Justiça (CNJ) buscam assegurar uma justiça mais célere e dar mais eficiência ao Judiciário, por meio da melhora da gestão do gerenciamento das rotinas de trabalho, a fim de aumentar a produtividade e reduzir o estoque processual.

A meta 1 consiste em julgar uma quantidade maior de processos de conhecimento do que os distribuídos no exercício anual. Verifica-se que a taxa de congestionamento das varas criminais em Palmas reduziu entre 2014 e 2015, conforme o gráfico 2. 


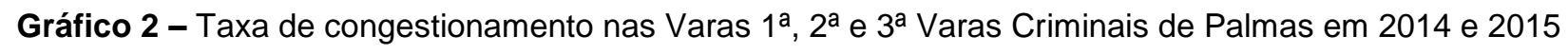

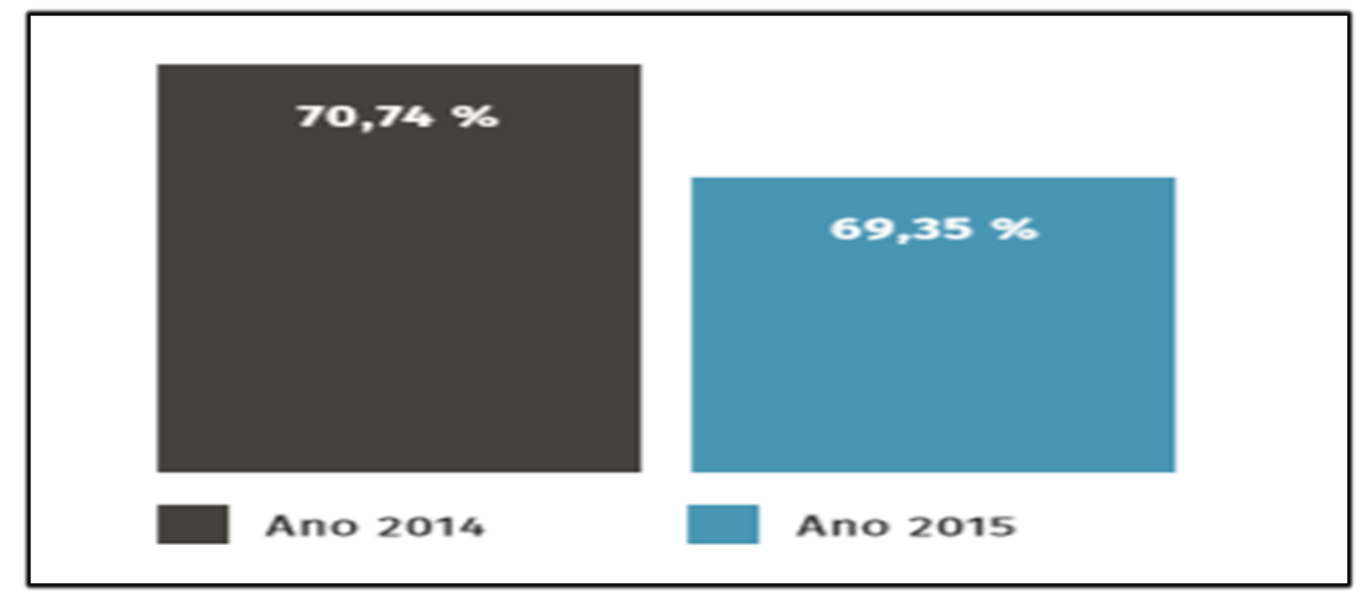

Fonte: TJTO (2015, p. 62).

Com vistas a solucionar o problema de congestionamento de processos, o TJTO lançou em 2016 uma ferramenta para facilitar a gestão da taxa de congestionamento nas varas e juizados em todo o estado, por meio dela, os magistrados têm acesso ao relatório diário de processos em trâmite na sua jurisdição. A ferramenta disponível no sistema do e-proc informa os magistrados sobre novos casos, entradas, saídas, casos baixados, julgados, dentre outros. De modo que, mede a efetividade dos trabalhos realizados e aponta os pendentes em determinado período.

Sobre a ferramenta o então diretor Judiciário do Tribunal de Justiça do Tocantins (TJTO), Francisco de Assis Sobrinho, responsável pela coordenadoria de processo eletrônico afirmou em 2016 que:

Uma taxa de congestionamento alta não quer dizer ausência de produtividade. Normalmente, são as formas de realizar os procedimentos cartorários que provocam os altos índices. Muitas vezes os magistrados até julgam um número de processos que poderia estar hoje em uma classificação melhor no ranking, mas se os processos não sofrerem baixa nas comarcas, a taxa vai ficar alta (TJTO ,2016, p. 01).

Assim como o aprimoramento da taxa de congestionamento de processos, o foco é o aperfeiçoamento de ações que impactem na melhora dos índices de congestionamento dos processos do TJTO, conforme a fixação do Conselho Nacional de Justiça. 


\section{CONSIDERACÕES FINAIS}

A informatização do processo judicial surgiu em decorrência de uma necessidade do Conselho Nacional de Justiça em dar celeridade ao sobrecarregado sistema de litígios dos Tribunais em todo o país. Sobre a implantação o estado do Tocantins esteve à vanguarda dos demais estados, sendo um dos primeiros a ter $100 \%$ dos processos digitalizados, por meio da ferramenta e-proc.

A utilização do e-proc. trouxe inúmeras vantagens aos operadores do Direito, magistrados e para a população como permitir em tempo real o acompanhamento da movimentação processual, maior transparência, redução de custos, proteção ao meio ambiente, melhoria da prestação jurisdicional devido à maior celeridade e produtividade do sistema.

Uma notável mudança que houve com a utilização do e-proc. corresponde à quantidade de processos físicos que preenchiam o espaço físico das comarcas, fóruns e tribunais prejudicando a qualidade de vida e salubridade do ambiente do Poder Judiciário. Atualmente, essa realidade mudou, pois os processos judiciais estão em formato digital.

Este estudo verificou que, com a implementação do e-proc. no Tribunal de Justiça do Tocantins houve a diminuição da taxa de congestionamento de processos em andamento nas varas e juizados, contanto, esta é uma linha tênue que precisa estar em continuo aprimoramento, seja por meio da capacitação de profissionais, de investimentos em novas tecnologias e equipamentos de informática, além do aumento do número de magistrados e servidores que operacionalizam o sistema e-proc.

Por fim, a implantação do processo judicial no TJTO otimizou a celeridade processual, a acessibilidade e a efetividade processual trazendo impactos positivos para o Poder Judiciário e proporcionando melhores condições para que os cidadãos tenham acesso à justiça.

\section{REFERÊNCIAS}

ABRÃO, Carlos Henrique. Processo Eletrônico. 3. ed. São Paulo: Atlas, 2011. 
ADORNO JÚNIOR, H. L.; MUNIZ, R. V. Os reflexos da implantação do processo judicial eletrônico sobre a saúde de seus sujeitos processuais. Universitas - Ano 2 - № 3 Julho/Dezembro 2016.

ALMEIDA FILHO, José Carlos de Araújo. Processo Eletrônico e Teoria Geral do Processo Eletrônico: A Informatização Judicial no Brasil. 3. ed. Rio de Janeiro: Forense, 2010.

. Processo eletrônico e teoria geral do processo eletrônico: a informatização judicial no Brasil. 5. ed. Rio de Janeiro: Forense, 2015.

BOBBIO, Norberto. A era dos Direitos. Rio de Janeiro: Campus, 1992.

BRASIL. Lei n. 11.419, de 19 de dezembro de 2006. Dispõe sobre a informatização do processo judicial; altera a Lei $n^{\circ} 5.869$, de 11 de janeiro de 1973 - Código de Processo Civil; e dá outras providências. Diário Oficial da União, Brasília, $185^{\circ}$ da Independência e $118^{\circ}$ da República, 19 dez. 2006.

.. Lei no 8.245/1991. Dispõe sobre as locações dos imóveis urbanos e os procedimentos a elas pertinentes. Casa Civil. Presidência da República, 1991.

BROTTO, Alexia Rodrigues. O processo eletrônico e a morosidade da justiça: alguns apontamentos sobre a Lei 11.419/06. Revista Bonijuris. Ano XXI, № 546, p. 10-16, mai/2009.

CAPPELLETTI, Mauro e Garth, Bryant. Acesso à Justiça. Porto Alegre: Sérgio Antônio Fabris Editor, 1988.

CHAVES, Luciano Athayde. A recente reforma no processo comum e seus reflexos no direito judiciário do trabalho. São Paulo: LTr, 2006.

CINTRA, Antônio Carlos Araújo; GRINOVER. Ada Pellegrini; DINAMARCO, Cândido Rangel. Teoria geral do processo. 26르 ed. São Paulo: Malheiros, 2010.

CINTRA. Teoria Geral do Processo. 14르 edição. São Paulo: Malheiros, 1998.

CNJ. Resolução no 125, de 29 de novembro de 2010. Conselho Nacional de Justiça. Dispõe sobre a Política Judiciária Nacional de tratamento adequado dos conflitos de interesse no âmbito do Poder Judiciário Nacional e dá outras providências. 2010.

.. Constituição da República Federativa do Brasil de 1988. Disponível em: www.planalto.gov.br/ccivil 03/constituicao/constituicao.htm. Acesso em: 10 fev. 2018. CONTEÚDO JURÍDICO (CONJUR). Vantagens e desvantagens do Processo Eletrônico. Disponível em: http://www.conteudojuridico.com.br/artigo,vantagensedesvantagens-do-processo-eletronico,45876.html. Acesso em: 05 abr. 2018.

DESTEFENNI, Marcos. Curso de Processo Civil. 2. ed. São Paulo: Saraiva, 2009. 
DINAMARCO, Cândido Rangel; GRINOVER, Ada Pellegrini e CINTRA, Antônio Carlos Araújo. Teoria Geral do processo. 22 ed. São Paulo: Malheiros, 2006.

FOLLE, Ana Júlia Cecconello; SHELEDER, Adriana Fasolo Pilati . As novas tecnologias e a uniformização do processo eletrônico: vantagem e desvantagens. 2014. Disponível em: http://publicadireito.com.br/artigos/?cod=e3998932e2e851de. Acesso em: 05 set. 2018.

GONÇALVES, Aidê Costa Bezerra. A aplicação dos meios alternativos na solução de conflitos pelo poder Judiciário Brasileiro, com enfoque na Justiça do Trabalho. Revista Âmbito Jurídico. 2016. Disponível em: http://www.ambitojuridico.com.br/site/index.php?n link=revista artigos leitura\&artigo id=17553\&revista C aderno=25. Acesso em: 05 ago. de 2018.

GONÇALVES, Raissa da Rocha Cunha. Os obstáculos enfrentados pelo processo judicial eletrônico na Justiça brasileira. E-Gov. 2015. Disponível em: http://www.egov.ufsc.br/portal/conteudo/os-obst\%C3\%A1culos-enfrentados-peloprocesso-judicial-eletr\%C3\%B4nico-na-justi\%C3\%A7a-brasileira. Acesso em: 20 fev. 2018.

GRECO, Marco Aurélio et al. Direito e Internet: Relações jurídicas na sociedade informatizada. São Paulo: Editora Revista dos Tribunais Ltda., 2001.

GRECO FILHO, Vicente. Direito Processual Civil Brasileiro. v. 1. 20. ed. rev. e atual. São Paulo: Saraiva, 2008.

MACHADO, Magali Cunha; MIRANDA, Fernando Silveira Melo Plentz. Lei no 11.419/06 - Processo Eletrônico. Revista Eletrônica Direito, Justiça e Cidadania - Volume 1 ํo $1-2010$.

MALLMANN, Felipe Hilgert. 0 processo (penal) eletrônico e o acesso à justiça no Brasil. Dissertação apresentada ao Programa de Pós-Graduação em Direito e Sociedade do Centro Universitário La Salle - UNILASALLE - Canoas, 2016.

MARQUES, R. P.; PEREIRA, S.S. O processo judicial eletrônico e as garantias constitucionais do processo. ANIMA: Revista Eletrônica do Curso de Direito das Faculdades OPET. Curitiba PR - Brasil. Ano VIII, 15, jul/dez 2016.

MEDINA, José Miguel Garcia. As vantagens e os problemas do processo eletrônico. Disponível em: http://professormedina.com/2011/09/15/as-vantagens-e-osproblemas-do-processo-eletronico. Acesso em: 06 abr. 2018.

ROCHA NETO, Paulo. O Processo Judicial Eletrônico Brasileiro. Dissertação de Mestrado em Engenharia Informática. Universidade Fernando Pessoa, Faculdade de Ciência e Tecnologia, Porto, Abril de 2015.

PAPA, Tereza Fernanda Martuscello. Vantagens e desvantagens do Processo Eletrônico. Conteúdo Jurídico. 18/11/2013. Disponível em: 
http://www.conteudojuridico.com.br/artigo,vantagens-e-desvantagens-doprocessoeletronico,45876.html. Acesso em: 10 jul. de 2018.

PAULA, Wesley Roberto de. Publicidade no Processo Judicial Eletrônico. São Paulo: LTR Editora, 2009.

PORTANOVA, Rui. Princípios do Processo Civil. Porto Alegre: Livraria do Advogado, 2005.

PRESTES, Maria da Graça Orsatto. Gestão ambiental no poder judiciário: Implementação de práticas administrativas ecoeficientes. IBRAJUS. 21/08/2007. Disponível em: http://www.ibrajus.org.br/revista/artigo.asp?idArtigo=27. Acesso em: 13 jul. de 2018.

SLONGO, Mauro Ivandro Dal Pra. O Processo Eletrônico Frente aos Princípios da Celeridade Processual e do Acesso à Justiça. Universo Jurídico, Juiz de Fora, ano XI, 05 de mai. de 2009.

SOARES, Tainy de Araújo. Processo judicial eletrônico e sua implantação no Poder Judiciário brasileiro. 2012. Disponível em: http://jus.com.br/artigos/22247. Acesso em: 20 jul. de 2018.

SOUSA, Luiz Antônio Da Silva. Do surgimento dos conflitos à importância de medidas extrajudiciais para resolvê-los. 2013. Disponível em: http://www.forummediacao.net/module2display. asp?id=39\&page=2. Acesso em: 28 set. de 2018.

TEIXEIRA, T. Curso de direito eletrônico e processo eletrônico: doutrina, jurisprudência e prática. $2^{\mathrm{a}}$ ed., São Paulo: Saraiva, 2014.

TOCANTINS. TJTO. Sistema e-Proc/TJTO: 1 milhão de processos. Notícia publicada em 03/05/2017. Tribunal de Justiça do estado do Tocantins. Disponível em: http://www.tito.jus.br/index.php/listagem-noticias/4729-sistema-e-proc-tito-1-milhao-deprocessos. Acesso em: 10 out. de 2018.

.TJTO. Relatório de atividades 2011. Produção Diretoria do Centro de Comunicação Social. Tribunal de Justiça do estado do Tocantins, 2012.

.TJTO. Relatório de atividades 2013. Produção Diretoria do Centro de Comunicação Social. Tribunal de Justiça do estado do Tocantins. 2014.

.TJTO. Relatório de Gestão 2013 a 2015. Tribunal de Justiça do Estado do Tocantins. Coordenação Vanusa Bastos. 2016.

.TJTO. Tocantins lança sistema de gestão de congestionamento de processos. (2016). Notícia publicada no site do CNJ. Disponível em: http://www.cnj.jus.br/noticias/judiciario/81524-tocantins-lanca-sistema-de-gestao-decongestionamento-de-processos. Acesso em: 06 out de 2018. 
.. Resolução № 005/2011 de 24 de outubro de 2011 do Estado do Tocantins em primeiro e segundo graus de jurisdição -. Palmas: 2011. Disponível em: www.tjto.jus.br. Acesso em: 17 set. de 2018.

.. Resolução № 001/2011 de 15 de fevereiro de 2011 - Implantação o processo eletrônico no âmbito do Poder Judiciário do Estado do Tocantins em primeiro e segundo graus de jurisdição - Palmas: 2011. Disponível em: www.tjo.jus.br. Acessado em: 17 set. de 2018.

VASCONCELOS, Carlos Eduardo de. Mediação de conflitos e práticas restaurativas. São Paulo: Método, 2008. 